\title{
Editorial
}

\section{Strategic Project Management and Leadership}

\author{
Amos Haniff ${ }^{\S}$ and Laura Galloway ${ }^{*}, \S$
}

School of Management \& Languages, Heriot-Watt University, Edinburgh, EH14 4AS, UK

It is with great pleasure that we present this collection of papers on Strategic Project Management and Leadership as a special issue in The Open Economics and Management Journal.

Significant growth in project organising across different industries and sectors over the past twenty years has evidenced that projects become an integral component of organizational strategic operations. Projects are now commonly viewed as suitable vehicles for business transformation, continuous improvement, organizational change and strategy implementation [1, 2]. As a consequence, there has been a growth of interest in strategic approaches to project management throughout the research community [3, 4]. This has shifted the focus from quantitative project control mechanisms and human recourses, that has underpinned traditional project management since the first edition of the Project Management Body of Knowledge [5], to inspection of the complexity of implementing strategy through projects and maintaining alignment of those projects with organizations', long-term, strategic aspirations [6-9].

By adopting a strategic project management approach to realizing strategic objectives, businesses are able to overcome traditional bureaucratic mechanisms and structures, which according to Burns and Stalker [10] are inherently resistant to change. Through effective leadership of portfolios, programmes and projects, organizations are to able respond to the rapid pace of change within the business environment. This requires an increased flexibility and autonomy amongst those who comprise project teams, including and especially affecting project leaders. Consideration of these person-centred, strategically-oriented strategies has not been possible within the traditional, deterministic, rational approach to understanding project management. For the development of these new approaches to projects, this special collection of works seeks to contribute.

This special issue on strategic project management and leadership explores projects in terms of their relationship with strategy in organizations and the critical role of

*Address correspondence to this author at the School of Management \& Languages, Heriot-Watt University, Edinburgh, EH14 4AS, UK;

Tel: +44(0)131 451 8286; E-mail: l.galloway@hw.ac.uk

${ }^{\S}$ Guest Editors leadership to align and lead strategically oriented projects. The collection starts with a paper by Torrance, et al. that identifies the difficulties associated with projects that span different locations and organisational forms. A particular problem is that as complexity increases in project numbers and structure, tangible links to a shared sense of strategic importance decrease. Another issue is the lack of clear lines of authority and in this sense, the paper identifies one of the key problems of leadership in projects generally. The paper suggests the Virtual Collaborative Organisation as a conceptualization that might be useful in terms of mitigating these overlapping issues.

Following this, in his paper 'In Pursuit of Relevance and Sustainability', Klakegg makes the case that alignment of projects to organizations' overall aims and objectives, is critical to adding value. Using a case example to illustrate, the paper identifies that dissemination of information relating to a project's greater strategic role and importance to those involved in that project is critical. Klakegg recommends various practical implementation approaches to managing this process so that effort within projects is focussed and appropriate, and optimal value added.

Biesenthal et al. explore the under-researched practice of time-management in complex project environments in their paper. They argue that context and projects cannot be separated conceptually if they are to make strategic contribution, and that management of the itinerant issues of uncertainty and ambiguity - as experienced in all organizations - must be managed appropriately also in projects.

Moving beyond the practice of managing projects in line with strategic aims in order to add value, the next few papers look specifically at the project manager. First, Patanakul links efficient strategic project management with the leadership of projects. Patanakul examines the processes organizations engage in to assign leaders to projects, and he questions if good strategic fit is always the driving force. As a consequence, a methodology by which project leader assignment might be optimized is developed in the paper, the purpose of which is to facilitate best value in terms of the strategic objectives of an organisation. Following on from this, Shenhar asks more directly, "What is Startegic Project Leadership?" In this paper, Shenhar makes the clear and direct case that leadership in projects, strategically aligned and integrated, is critical in and across organizations. The paper identifies in some detail the requirement of the field of project management to engage with the strategy and 
leadership literatures to develop beyond the traditional practice base. In order for knowledge, theory, and in turn practice, to continue to be relevant, new approaches to understanding value and value potential of strategic project management and strategic leadership in projects are required. Shenhar's detailed conceptualization of Strategic Project Leadership is presented for this purpose.

The last paper in this special issue takes the ideas of strategic project management and strategic project leadership and reports their application and utility in the architecture industry. Galloway and Haniff demonstrate that as a creative sector, architecture requires projects to be led within a context that demands both traditional, time-bound, task orientation, but also person-base leadership styles in order to best facilitate the creative process. Consequently, the authors identify that there is much to be gained in project management as a discipline from engaging with extant leadership theory and empirical study. Indeed, this message is one of the clear outcomes of the special issue in general. Project management as a field of study - or as a unit of analysis -is firmly rooted in operations-based modes of understanding and enquiry. As all the papers included in this special issue suggest, in the modern, global world the contribution of projects is potentially much greater than an exclusively operational framework that would allow us to explore. We know that strategic alignment and leadership are important, and scholars have agreed that there is much to be gained in terms of value for organizations in engaging with conceptualisations and approaches to understanding projects that stress the importance of the people occupied in them. Both the strategy and the leadership literatures might inform the development of project management and facilitate the emergence of new conceptualisations, such as project leadership. We hope that you would appreciate that this special issue has provided some preliminary steps at its best.

\section{REFERENCES}

[1] Maylor H. Beyond the Gantt chart: project management moving on. Eur Manage J 2001; 19(1): 92-100.

[2] Winter M, Smith C, Morris P, Cicmil S. Directions for future research in project management: the main findings of a UK government-funded research network. Int J Proj Manage 2006; 24(8): 638-49.

[3] Crawford L, Hobbs B, Turner JR. Aligning capability with strategy: categorizing projects to do the right projects and to do them right. Proj Manage J 2006; 37(2): 38-50.

[4] Kwak YH, Anbari FT. Analyzing project management research: Perspectives from top management journals. Int J Proj Manage 2009; 27(5): 435-46.

[5] PMI. Project Management Body of Knowledge of The Project Management Institute (PMI). Upper Derby, IL: Project Management Institute 1987.

[6] Cicmil S, Hodgson D. Making projects critical: an introduction. In: Hodgson D, Cicmil S, Eds. Making projects critical. New York: Palgrave MacMillan 2006; pp. 1-25.

[7] Gareis R. Management by projects: the management strategy of the 'new' project-oriented company. Int J Proj Manage 1991; 9(2): 716.

[8] Cleland DI, Ireland LR. Project management: strategic design and implementation $5^{\text {th }}$ ed. New York: McGraw-Hill, Inc 2006.

[9] Turner JR, Keegan A. The versatile project-based organization: governance and operational control. Eur Manage J 1999; 17(3): 296-309.

[10] Burns T, Stalker GM. The management of innovation. Revised ed. Oxford; New York: Oxford University Press 1994.

(C) Haniff and Galloway; Licensee Bentham Open.

This is an open access article licensed under the terms of the Creative Commons Attribution Non-Commercial License (http://creativecommons.org/licenses/by$\mathrm{nc} / 3.0 /$ ) which permits unrestricted, non-commercial use, distribution and reproduction in any medium, provided the work is properly cited. 